\title{
Determination and stability testing method of chlorpheniramine maleate in the presence of tartrazine using HPLC
}

\author{
Asri Darmawati*, Febri Annuryanti, Riesta Primaharinastiti, Isnaeni \\ Department of Pharmaceutical Chemistry, Faculty of Pharmacy, Universitas Airlangga \\ Nanizar Zaman Joenoes Building \\ Jl. Dr. Ir. H. Soekarno, Surabaya, East Java, Indonesia
}

Submitted: 21-07-2020

Reviewed: 25-08-2020

Accepted: 26-09-2020

\begin{abstract}
The single-component CPM tablet mostly used sodium tartrazine as the yellow coloring agent. Sodium tartrazine is soluble in solvents used to extract CPM from tablet and suspected interference CPM determination, especially after forced degradation for stability indication testing of CPM tablets. This study aimed to develop a selective, accurate and precise method for determination and stability testing of chlorpheniramine maleate (CPM) in the presence of tartrazine in the tablet. A $\mu$ Bondapak $^{\circledR}$ C18 column $(3.9 \times 300 \mathrm{~mm}, 10 \mu \mathrm{m})$ with a diode array detector was used for separation. The mobile phase was a mixture of methanol and $0.2 \%$ triethylamine (90:10) with a flow rate of $2 \mathrm{~mL} /$ minutes. The validated HPLC method was used for CPM determination in tablet samples that had been forced degraded using dry heat at $105^{\circ} \mathrm{C}$, UV radiation of $254 \mathrm{~nm}$, hydrolysis with $1 \mathrm{~N} \mathrm{NaOH}, 1 \mathrm{~N} \mathrm{HCl}$, and oxidation using $5 \% \mathrm{H}_{2} \mathrm{O}_{2}$. The HPLC chromatogram showed that CPM split into chlorpheniramine (CP) and maleic acid (MA). Resolution (Rs) among CP and the other analytes, especially with the products resulting from the forced degradation by heat, $\mathrm{UV}$ radiation, $\mathrm{HCl}$, and $\mathrm{H}_{2} \mathrm{O}_{2}$, were good. The $\mathrm{CPM}$ hydrolysis using $\mathrm{NaOH}$ caused the $\mathrm{CP}$ not completely separated from the degradation product due to tailing or overlapping peaks. The proposed HPLC method was valid for the determination of CPM in tablets containing tartrazine. Even though the stability-indicating method was inadequate especially for the result of the CPM hydrolysis process using $\mathrm{NaOH}$.
\end{abstract}

Keywords: chlorpheniramine maleate, tartrazine, stability-indicating method, HPLC

\author{
*Corresponding author: \\ Asri Darmawati \\ Faculty of Pharmacy, Universitas Airlangga \\ Nanizar Zaman Joenoes Building \\ Jl. Dr. Ir. H. Soekarno, Surabaya, East Java, Indonesia \\ Email: asri-d@ff.unair.ac.id
}




\section{INTRODUCTION}

Chlorpheniramine maleate or (CPM) is one of the most widely used classical antihistamines (AH1). The mild sedative side effect of CPM misused to stimulates sleepiness in people with insomnia. The CPM tablet is prescribed for many allergic reactions, such as rhinitis, conjunctivitis, mild urticaria, and angioedema. Also, CPM is used as an adjunctive therapy in anaphylactic shock. Generally, a single component CPM tablet is in yellow with the yellow coloring agent mostly used is sodium tartrazine (C.I No.19140 or FD\&C No.5). Molecular structures of CPM and sodium tartrazine are shown in Figure 1 (Klorfeniramin Maleat, 2014; Srinivasan and Kawamura, 2016).

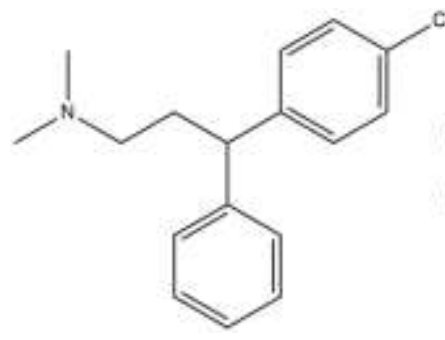

Chlorpheniramine maleate

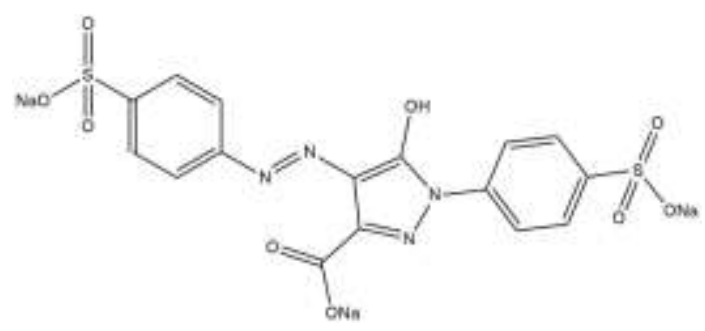

Tartrazine

Figure 1. Molecular structures of chlorpheniramine maleate and tartrazine

Both CPM and tartrazine are soluble in water, methanol, ethanol, $0.1 \mathrm{~N} \mathrm{HCl}$, and $0.1 \mathrm{~N} \mathrm{NaOH}$. Therefore, tartrazine is suspected interference CPM determination especially in a stability indication study of CPM tablets. The stability study is carried out in stress conditions to degrade substance in the pharmaceutical product. To obtain degradants, stress parameters (thermal, UV radiation, oxidation, acids, and alkali hydrolysis) can be applied in a shorter span time (Blessy et al., 2014). The degradants obtained from forced degradation of CPM tablets can be derived from CPM as active ingredients or from tablet additives, such as tartrazine. Although the determination of CPM in a mixture with CPM related compounds B, C, and other impurities has been presented (Karikalan et al., 2016), the stability indicating method for CPM tablets in the presence of tartrazine has not been reported yet.

Several methods have been proposed for CPM determination in the mixture with the other substance in pharmaceutical products, such as spectrophotometry with Principal Component Regression (PCR) analysis (Darwish et al., 2015b), High-Performance Thin Layer Chromatography (HPTLC)-densitometry (Darwish et al., 2015a), High- Performance Liquid Chromatography (HPLC or RP-HPLC) (Chlorpheniramine Maleate, 2016a), and potentiometric (Saleh, 2011).

In the present study, we reported the validation of HPLC method for CPM determination in a tablet containing tartrazine and its application for stability-testing of CPM. Three registered CPM tablets containing tartrazine (coded $\mathrm{AD} \AA, \mathrm{AL} \AA$, and $\mathrm{ZE} \AA$ ) were used as a model tablet for obtaining the HPLC chromatogram profile of CPM after the forced degradation process.

\section{MATERIALS AND METHOD}

\section{Materials}

UFLC Shimadzu LC-20AD/T with diode array detector and $\mu$ Bondapak $^{\circledR}$ C18 3.9x300 mm, 10 $\mu \mathrm{m}$, column. Analytical balance (Metler Toledo), soccorex micropipette $(\mathrm{d}=1.0 \mu \mathrm{L})$ vortex (Genius 3), centrifuge apparatus (EBA20 Hectic), ultrasonic bath (Branson 3510).

Chlorpheniramine maleate standard material was procured from the National Drug and Food Control Agency of The Republic of Indonesia. This substance was dried at $105^{\circ} \mathrm{C}$ for 3 hours before use. Methanol, triethylamine, ethyl acetate, isopropanol, ammonium hydroxide, hydrogen peroxide, hydrochloric acid, and sodium hydroxide were analytical reagent grade (Merck). Tartrazine (food 
grade, a gift from Aditama Raya Pharmaceutical Industry) and three commercially registered CPM tablet brands (coded $\mathrm{AD} \AA$, AL®, and ZE®) w

\section{Methods}

\section{Preparation of CPM and tartrazine solution}

The CPM and tartrazine were prepared by dissolving an accurately weight of $60 \mathrm{mg}$ of CPM and tartrazine standard with solvent in $10 \mathrm{~mL}$ volumetric flasks. The CPM working solution was diluted to obtain CPM concentrations in the range of $500-5000 \mu \mathrm{g} / \mathrm{mL}$, while tartrazine was diluted to provide a concentration in the range of $400-4000 \mu \mathrm{g} / \mathrm{mL}$. All solutions were filtered through Whatman filter paper of $0.2 \mu \mathrm{m}$ pores prior to injecting in HPLC. A mixture of methanol and water $(1: 1, \mathrm{v} / \mathrm{v})$ was used as a solvent in this experiment. The solutions were analyzed using HPLC optimum condition with a flow rate of $2 \mathrm{~mL} /$ minute and detected at a wavelength of $262 \mathrm{~nm}$.

\section{Preparation of tablet matrix}

Compositions of tablet matrix was as follows: Avicel (4.500 gram), lactose (4.500 gram), starch (0.750 gram), magnesium stearate (0.300 gram), talc (0.250 gram) (Ali et al., 2011), and tartrazine (15 $\mathrm{mg}$ ). All the matrix compounds mixed homogeneously in a mortar. A weight of CPM tablet assumed $150 \mathrm{mg}$ and contains $4 \mathrm{mg}$ of CPM.

\section{Preparation of artificial tablet solution}

For accuracy and precision study, each tablet matrix of $900 \mathrm{mg}$ was added with $1.0 \mathrm{~mL}, 2.0 \mathrm{ml}$ and $4.0 \mathrm{~mL}$ of $6000 \mu \mathrm{g} / \mathrm{mL}$ CPM solution in the different $10 \mathrm{~mL}$ volumetric flasks. A mixture of methanol: water $(1: 1)$ as solvent was added in the volumetric flask up to two-third of a total volume. The volumetric flask was agitated in an ultrasonic bath for 15 minutes before agitation on a vortex apparatus for 5 minutes. The suspension then added with solvent up to $10.0 \mathrm{~mL}$. The suspension was transferred into covered tubes and centrifuged at $3000 \mathrm{rpm}$ for 15 minutes. The supernatant was filtered using a filter paper of $0.2 \mu \mathrm{m}$ pore. About $20 \mu \mathrm{L}$ filtrate injected in the HPLC instrument.

\section{Preparation of tablet samples solution}

Twenty tablets of a registered CPM tablet were weighted and powdered homogenously. A portion of the powdered tablet equivalent to $24 \mathrm{mg}$ of CPM was weighted accurately and processed according to the preparation of an artificial tablet solution that had been described above (without standard CPM solution addition).

\section{Validation}

\section{Optimization of mobile phase}

A stock solution of CPM and tartrazine was pipetted to make a solution containing $2000 \mu \mathrm{g} / \mathrm{mL}$ CPM and $400 \mu \mathrm{g} / \mathrm{mL}$ of tartrazine. The solution was analyzed using various compositions of the mobile phase containing methanol, water, and triethylamine (TEA). The optimum analysis condition was obtained if resolution (Rs) value between CPM and the other components was > 1.5.

\section{Selectivity}

The method's selectivity was determined by the similarity of retention time $\left(t_{R}\right)$ between CPM sample peak compared with CPM standard, the peak purity, spectra profile, and the Rs value.

\section{Linearity}

The CPM concentration (X) versus CPM area (Y) linearity was tested using CPM standard solution in the range concentration of $500-5000 \mu \mathrm{g} / \mathrm{mL}$. The linearity parameter was the coefficient determination $\left(\mathrm{R}^{2}\right)$ value of more than 0.99 . 


\section{Accuracy and precision}

The accuracy parameter was the percentage recovery of CPM standard that added quantitatively to the tablet matrix. The final concentration of CPM standard added in the artificial tablet solution was in the range of $500-2400 \mu \mathrm{g} / \mathrm{mL}$. The precision parameter was the coefficient variation $(\mathrm{CV})$ of the percentage of CPM recoveries.

\section{Forced degradation}

\section{Degradation using UV radiation}

Two milliliters of $2000 \mu \mathrm{g} / \mathrm{mL}$ CPM in the artificial tablet solution and tablet samples solution were put into different closed test tubes. The tubes were exposed under UV radiation at a wavelength of $254 \mathrm{~nm}$ for $2 \times 24$ hours in the closed wood box (Kommana and Basappa, 2013). Finally, the solutions were added with the solvent up to $5.0 \mathrm{~mL}$ in the volumetric flask. A control solution was made from a solution with the same composition but not exposure to UV radiation.

\section{Degradation using thermal of $105^{\circ} \mathrm{C}$}

A mixture of tablet matrix containing CPM standard and the sample of CPM tablets (equivalent to $16 \mathrm{mg}$ of $\mathrm{CPM}$ ) was put in a closed glass tube and heated in the oven at $105^{\circ} \mathrm{C}$ for $2 \mathrm{x} 24$ hours (Kommana and Basappa, 2013). After cooling, the sample was added with $5.0 \mathrm{~mL}$ of solvent and processed as same as the tablet sample solution.

\section{Degradation using $5 \% \mathrm{H}_{2} \mathrm{O}_{2}$}

Two milliliters of $2000 \mu \mathrm{g} / \mathrm{mL}$ CPM in an artificial tablet solution and tablet samples solution were put into different closed test tubes. The liquids were added with $1.0 \mathrm{~mL}$ of $15 \% \mathrm{H}_{2} \mathrm{O}_{2}$ before heated in a water bath at $90^{\circ} \mathrm{C}$ for 2 hours (Alagić-Džambić et. al., 2014; Ali et al., 2016). After cooling, the liquids were transferred into volumetric flasks and added with the solvent up to $5.0 \mathrm{ml}$ in the volumetric flask. The liquid obtained was filtered using Whatman paper filter of the $0.2 \mu \mathrm{m}$ pore. Finally, the filtrate was analyzed using HPLC. The CPM control solution was the same composition of liquid sample that was processed without $\mathrm{H}_{2} \mathrm{O}_{2}$ reagent additions.

\section{Degradation using $1 \mathrm{~N} \mathrm{NaOH}$}

Two milliliter of $2000 \mu \mathrm{g} / \mathrm{mL}$ CPM in artificial tablet solution and tablet samples solution were put into different closed test tubes. The liquids were added with $0.5 \mathrm{~mL}$ of $5 \mathrm{~N} \mathrm{NaOH}$ solution before heating in a water bath at $90^{\circ} \mathrm{C}$ for 2 hours (Alagić-Džambić et al., 2014; Ali et al., 2016). After cooling, the liquids were transferred into the volumetric flask and added with $0.5 \mathrm{~mL}$ of $5 \mathrm{~N} \mathrm{HCl}$ solution to neutralize the $\mathrm{pH}$ of the liquid. Further, the solvent was added up to $5.0 \mathrm{~mL}$ in the volumetric flask (check the $\mathrm{pH}$ with universal $\mathrm{pH}$ indicator paper). The liquid obtained was filtered using Whatman paper filter of $0.2 \mu \mathrm{m}$ pore. Finally, the filtrate was analyzed using HPLC. The CPM control solution was prepared in the same composition of liquid samples that processed without $\mathrm{NaOH}$ and $\mathrm{HCl}$ reagent additions.

\section{Degradation using 1N HCl}

The artificial and sample of tablet solution were processed with the same manner as the degradation process using $\mathrm{NaOH}$ reagent above. The final solution neutralized using $\mathrm{NaOH}$.

\section{RESULT AND DISCUSSION Validation of the method Selectivity}

The HPLC chromatogram profile of CPM standard and CPM tablets containing tartrazine were presented in Figure 2 and Figure 3, respectively. The mobile phase of methanol and 0.2\% TEA (90:10) 
with a flow rate of $2 \mathrm{~mL} /$ minute was optimally separated $\mathrm{CP}$ from the other substances in the sample. Analytes were detected at a wavelength of $262 \mathrm{~nm}$. The CPM was separated in two main peaks, as chlorpheniramine (CP) and maleic acid (MA) with the retention time of 4.07 and 1.01 minutes, respectively. This retention time $\left(t_{R}\right)$ was shorter than in the previous studies (Karikalan et al., 2016; Kommana and Basappa, 2013).

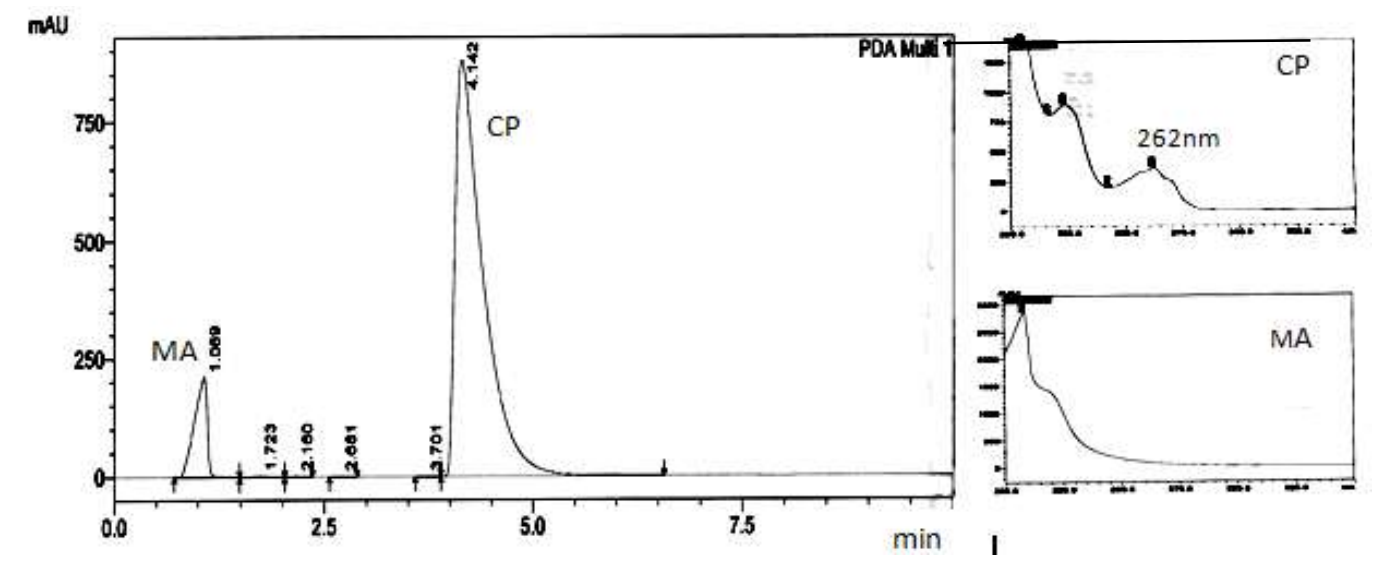

Figure 2. Chromatogram of CPM standard $2744 \mathrm{ppm}$ inserted with UV spectra profile of chlorpheniramine (CP) and maleic acid (MA)
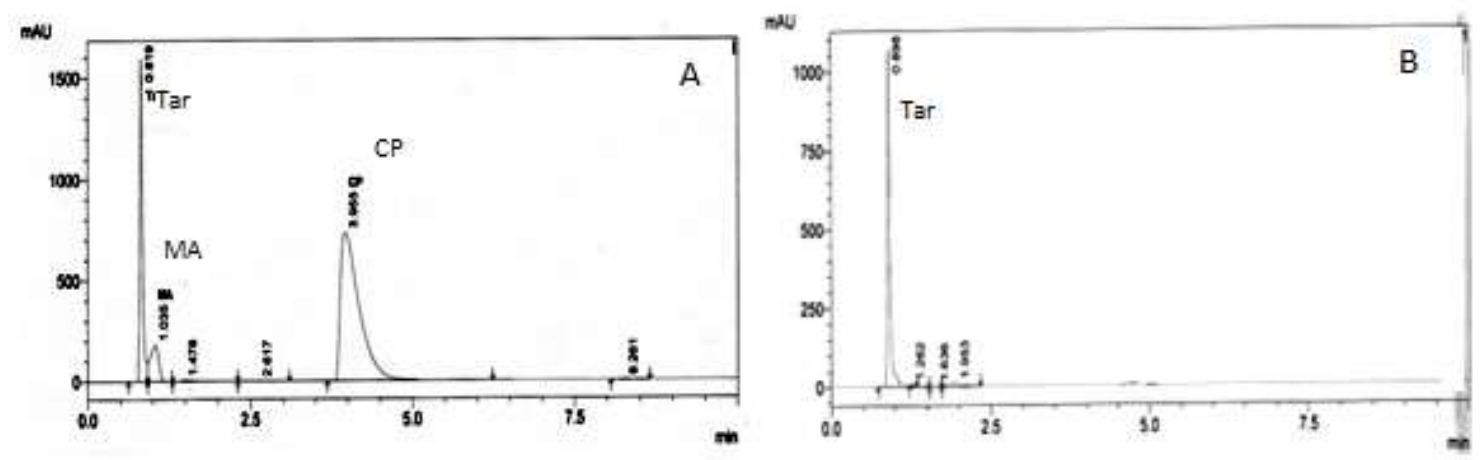

Figure 3. Chromatogram of (A) CPM sample coded AL®, and (B) tablet matrix

The sample chromatogram (Figure 3$)$ showed that tartrazine $\left(t_{R}=0.80\right.$ minutes) was separated from CP but not completely separated from MA. The overlapping of tartrazine and MA peaks was not affected the CPM determination because the recovery of CPM was based on the CP area. The average resolution (Rs) between $\mathrm{CP}$ and the nearest $\mathrm{CP}$ impurity was 1.10. Tailing factor of $\mathrm{CP}$ was 2.76. The analytes peak that consistently emerged in the CPM standard chromatogram and their average relative response compared to CP signal area were listed in Table 1.

Table 1. Analytes peak profile of CPM standard chromatogram

\begin{tabular}{lcccccc}
\hline \multirow{2}{*}{ Analyte } & \multirow{2}{*}{$\mathrm{MA}$} & 1 & 2 & 3 & 4 & $\mathrm{CP}$ \\
\hline $\mathrm{t}_{\mathrm{R}}$ (minutes) & 1.01 & 1.73 & 2.17 & 2.70 & 3.60 & 4.07 \\
Relative $\mathrm{t}_{\mathrm{R}}$ compared to CP & 0.25 & 0.43 & 0.53 & 0.65 & 0.89 & 1,00 \\
Resolution & 0.00 & 0.15 & 0.36 & 0.62 & 3.50 & 1.10 \\
Relative signal area (\%) & 11.17 & 0.249 & 0.087 & 0.024 & 0.013 & 100 \\
\hline
\end{tabular}




\section{Linearity}

The CPM concentration over the range of $400-4000 \mu \mathrm{g} / \mathrm{mL}$ showed a linear relationship with the CP and MA area. The coefficient determination $\left(\mathrm{R}^{2}\right)$ and the linear regression equation of CPM were listed in Table 2. The average percentage of the MA area compared with the $\mathrm{CP}$ area was (11.51 $\pm 0.29) \%$. Therefore, the determination of CPM based on CP area is better than based on MA area.

Table 2. Result of linearity test

\begin{tabular}{llll}
\hline $\begin{array}{l}\text { CPM concentration } \\
(\mathrm{ppm})\end{array}$ & $\begin{array}{l}\text { CPM area } \\
(\mathrm{mAU})\end{array}$ & $\begin{array}{l}\text { MA area } \\
(\mathrm{mAU})\end{array}$ & $\begin{array}{l}\text { Percentage area } \\
\text { MA/CPM }(\%)\end{array}$ \\
\hline 426.7 & 2972966 & 348156 & 11.71 \\
640.0 & 3859254 & 462885 & 11.99 \\
853.3 & 6089495 & 708873 & 11.64 \\
1600 & 11536389 & 1294239 & 11.22 \\
2400 & 16190532 & 1819690 & 11.24 \\
3200 & 22308217 & 2513498 & 11.27 \\
4800 & 32180338 & 3690885 & 11.47 \\
\hline Linear equation & $6753.4 \mathrm{x}+161326$ & $767.42 \mathrm{x}+22255$ & \\
$\mathrm{R}^{2}$ & 0.9982 & 0.999 & \\
Vxo & $3.68 \%$ & $2.77 \%$ & \\
\hline
\end{tabular}

\section{Accuracy and precision}

The accuracy and intermediate precision of HPLC for the determination of CPM in an artificial tablet containing tartrazine were in the range of requirements (AOAC International, 2013), as listed in Table 3. The CPM range concentration of (25-100) \% was used for the anticipation of decreasing CPM concentration in the forced degradation process.

Table 3. Result of accuracy and precision test of HPLC for CPM determination in an artificial tablet

\begin{tabular}{llll}
\hline $\begin{array}{l}\text { Percentage of CPM } \\
\text { concentration }\end{array}$ & $\begin{array}{l}\text { CPM concentration } \\
(\mathrm{ppm})\end{array}$ & $\begin{array}{l}\text { CPM recovery } \\
(\mathrm{ppm})\end{array}$ & $\begin{array}{l}\text { CPM recovery } \\
(\%)\end{array}$ \\
\hline $25 \%$ & 591.0 & 583.8 & 98.79 \\
& 634.0 & 634.6 & 100.1 \\
$50 \%$ & 603.0 & 630.1 & 104.5 \\
& 1182 & 1156 & 97.78 \\
& 1268 & 1239 & 97.69 \\
$100 \%$ & 1206 & 1166 & 96.71 \\
& 2740 & 2793 & 101.93 \\
& 2560 & 2545 & 99.41 \\
Average & 2700 & 2820 & 104.40 \\
SD & & $100.14^{\mathrm{a}}$ \\
CV $(\%)$ & & $2.87^{\mathrm{b}}$ \\
\hline a) & & & 2.86 \\
\hline
\end{tabular}

a) (AOAC International, 2013) requirement was (97-103)\%

b) (AOAC International, 2013) requirement was 3\%

Determination of $\mathrm{CPM}$ in tablet samples (coded $\mathrm{AD} \AA$, $\mathrm{AL} \AA$, and $\mathrm{ZE} \circledast$ ), that have been checked previously containing tartrazine, listed in Table 4 . The CPM concentrations in tablet samples were in the range of CPM label amount of (90-110)\%, fulfilled the pharmacopoeia requirements, which is $90.0-110.0 \%$ of the label amount (Chlorpheniramine Maleate, 2016a). 
Table 4. Result of CPM determination in the tablet samples

\begin{tabular}{lllc}
\hline \multirow{2}{*}{ Replicate } & \multicolumn{3}{l}{ Percentage of CPM according to the label of CPM amount in tablet sample } \\
& AD® & AL® & ZE® \\
\hline 1 & 96.65 & 102.2 & 101.4 \\
2 & 97.90 & 100.1 & 101.7 \\
3 & 97.90 & 104.3 & 97.65 \\
\hline Average & 97.49 & 102.2 & 100.26 \\
SD & 0.58 & 1.71 & 1.85 \\
CV $(\%)$ & 0.59 & 1.67 & 0.84 \\
\hline
\end{tabular}

\section{Forced degradation of CPM tablets}

\section{Degradation in UV radiation exposure}

The HPLC chromatogram of the artificial tablet solution after exposure in a UV radiation at $254 \mathrm{~nm}$ for $2 \times 24$ hours was identical with the chromatogram of the CPM sample solutions, as depicted in Figure 3. The tartrazine, MA, and degradants separated from the CP peak. The CPM concentrations in samples AL ${ }^{\circledR}$ and $\mathrm{ZE} \circledast$ tend to decrease, while the CPM in the artificial mixture and sample $A D \circledR$ were relatively the same as the initial concentration (Table 4 and Table 5).

Figure 3. Chromatogram of (A) CPM sample coded ALß, and (B) tablet matrix

Table 5. Result of CPM determination in samples after the forced degradation process

\begin{tabular}{lllllll}
\hline \multirow{2}{*}{ No } & \multirow{2}{*}{ Samples } & \multicolumn{4}{c}{ Percentage of CPM concentration compared with control after degradation process using } \\
& & UV 254 nm & Thermal $105^{\circ} \mathrm{C}$ & $1 \mathrm{~N} \mathrm{NaOH}$ & $1 \mathrm{~N} \mathrm{HCl}$ & $5 \% \mathrm{H}_{2} \mathrm{O}_{2}$ \\
\hline 1 & Artificial mix & 103.97 & 69.38 & 89.50 & 100.39 & 91.82 \\
2 & AD® tablet & 98.40 & 81.99 & 113.65 & 85.85 & 94.33 \\
3 & AL® tablet & 91.39 & 80.70 & 110.76 & 91.92 & 92.91 \\
4 & ZE® tablet & 94.25 & 91.25 & 18.86 & 97.70 & 92.72 \\
\hline
\end{tabular}

\section{Degradation using thermal of $105^{\circ} \mathrm{C}$}

The chromatogram profile of the artificial tablet after thermal degradation was identical to all tablet sample chromatograms (Figure 4A). The CP peaks separated from tartrazine and degradants peak. The area of some degradation products increased, while the CPM recovery decreased (Table 5). Also, the yellow colour of the sample powder turned to black. The drying time of CPM standard before used was $105^{\circ} \mathrm{C}$ for 3 hours, which meant that CPM is relatively stable (Chlorpheniramine Maleate, 2016a). However, heating for a long time made CPM and additional ingredient decomposed.

\section{Oxidation using $\mathrm{H}_{2} \mathrm{O}_{2}$}

Sample degradation using $5 \% \mathrm{H}_{2} \mathrm{O}_{2}$ and heated at $90^{\circ} \mathrm{C}$ for 2 hours in the water bath did not change the yellow colour of the CPM sample solution. But, the chromatogram showed that the degradation products area increased (Figure 4B) in comparison with the initial chromatogram (Figure 3). CPM concentrations tend to decrease (Table 5). The analyte at $t_{R}$ of 2.66 minutes suspected as CPM Related Compound B (CRCB) because it had a spectra profile similar to CP ( $t_{R}$ of $\left.4.1 \mathrm{~min}\right)$. The CPM related compound B is $N$-(pyridine-2-yl) pyridine-2-amine (2, 2'-dipyridylamine) (Chlorpheniramine Maleate, 2016a; Chlorpheniramine Maleate, 2016b). The suspect CRCB was not yet confirmed with MS data 

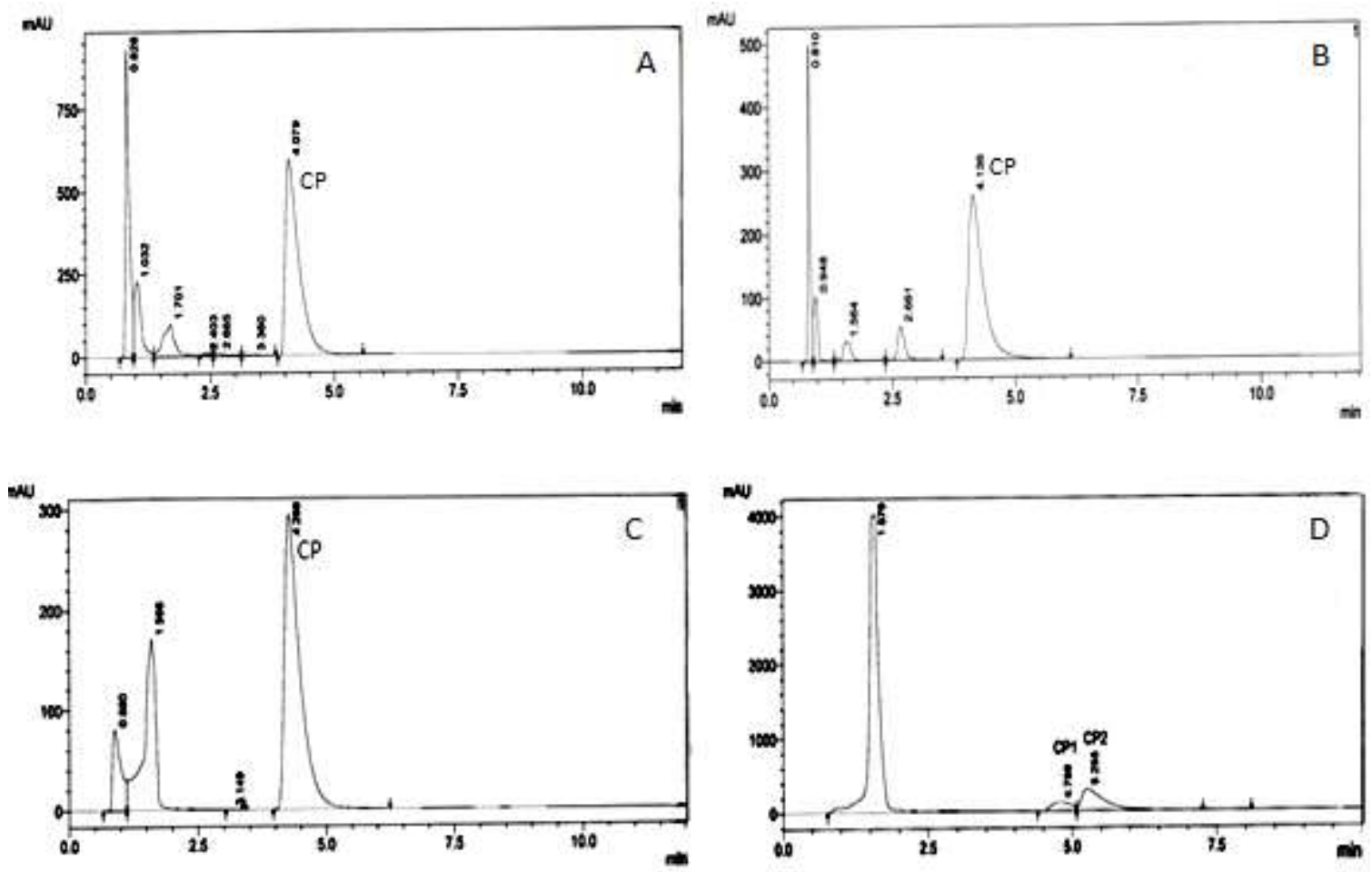

Figure 4. Chromatogram of CPM tablet sample coded $\mathrm{Al}^{\circledR}$ after exposed (A) in the oven at $105^{\circ} \mathrm{C}$ for 2 days, (B) $5 \% \mathrm{H}_{2} \mathrm{O}_{2}$, (C) $1 \mathrm{~N} \mathrm{HCl}$ and (D) $1 \mathrm{~N} \mathrm{NaOH}$

\section{Hydrolysis in $1 \mathrm{~N} \mathrm{HCl}$}

The hydrolysis using $1 \mathrm{~N} \mathrm{HCl}$ at $90^{\circ} \mathrm{C}$ for 2 hours did not change the yellow color of the CPM solution. Some retention time of analytes shifted to a longer one, tartrazine and MA peaks overlapped, but the resolution between the CP's peak with the nearest peaks was good as shown in Figure 4C. The CPM concentrations in the sample tend to decrease, but CPM in the artificial mixture was not different from the initial concentration of CPM (Table 5). The variation of $\mathrm{pH}$ adjustment after the degradation process caused several retention times of analytes in the final sample solution shifted. It was difficult to neutralize the sample solution precisely.

\section{Hydrolysis in $1 \mathrm{~N} \mathrm{NaOH}$}

The hydrolysis using $1 \mathrm{~N} \mathrm{NaOH}$ at $90^{\circ} \mathrm{C}$ for 2 hours made the yellow color of the CPM sample liquid turn to brown, some tablet ingredients were denatured and the sample was difficult to be filtered. Most analyte retention time shifted to a longer one as shown in Figure 4D. The variation of $\mathrm{pH}$ adjustment of the final solution presumed as the cause of shifted $t_{\mathrm{R}}$ (Figure 4C, 4D). The peaks of $\mathrm{CPM}$ in sample coded $\mathrm{AD}$ and $\mathrm{Al}$ showed single peak, but an artificial mixture and sample $\mathrm{Ze} \circledast$ split to be two peaks (Figure 4D). The UV spectra profile of the split CP peaks at tR of 4.7 minutes (CP1) was similar to a peak of 5.2 minutes (CP2), as shown in Figure 5. The three points of purity of CP1 and CP2 peaks were 0.999 and 0.944 , respectively. The split peak would decrease the CPM recovery. This result is consistent with a stability study done by Raghu et al., revealed that pheniramine maleate was degraded in the base condition (Raghu et al., 2012). Nevertheless, if the shift CP peak overlapped with the degradant/other analytes as might be happened in sample coded AD and Al, which look liked a single peak (not shown in this manuscript), the $\mathrm{CP}$ recovery would be higher than it should be. 
Especially if the other analytes are more sensitive than CP. This condition made the CPM determination was not precise and needed further study.
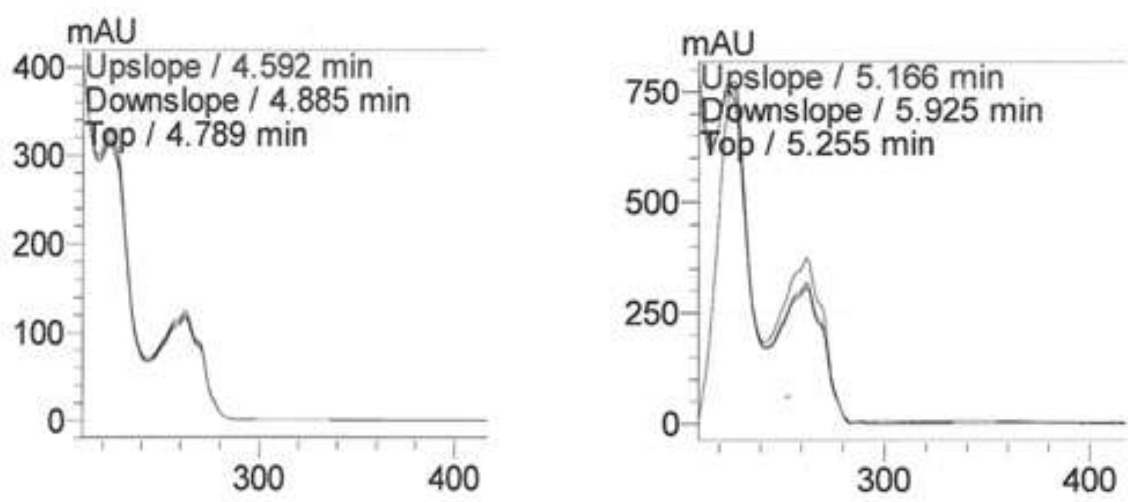

Figure 5. The UV spectra profile of analyts with $t_{R}$ of $4.7 \mathrm{~min}(\mathrm{CP1})$ and $5.26 \mathrm{~min}$ (CP 2) of the chromatogram of artificial CPM tablet after hydrolysis with $1 \mathrm{~N} \mathrm{NaOH}$

The chromatography condition for degraded sample analysis was using the mobile phase of methanol and $0.2 \%$ TEA (90:10) with a flow rate of $2 \mathrm{~mL} /$ minute, ambient column temperature and detected at a wavelength of $262 \mathrm{~nm}$.

This study showed that tartrazine separated from CP with Rs of $>1.5$. Tartrazine is a dye anion that presents in the hydrazone form at $\mathrm{pH} 7$ and the azoform at $\mathrm{pH} 12$ (Srinivasan and Kawamura, 2016). Tartrazine was not completely separated from MA, especially after the forced degradation process. The addition of $0.2 \%$ TEA as quaternary ammonium in the mobile phase would increase the polarity of the stationary phase and reduce the tailing of CP peak. The acidic substance (MA and tartrazine) were immediately eluted from the column because both of the substances did not interact tightly with $\mathrm{Si}-\mathrm{OH}$ in the column. Even though the $\mathrm{CP}$ was separated from MA as an acidic part of CPM, the composition of MA to CP was constant (Table 2). The CP area can be used as the base calculation for CPM concentrations.

In the reference, relative $t_{R}$ of analyte peaks in CPM bulk material chromatogram are 0.18, 0.37, 0.49, 0.97, 1.0, and 1.19 (Chlorpheniramine Maleate, 2016a). The peaks were derived from MA (maleic acid), diamine analogue, CRCB (chlorpheniramine related compound B), CRCC (chlorpheniramine related compound $\mathrm{C}$ ), $\mathrm{CP}$ (chlorpheniramine), and chlorpheniramine nitrile, respectively; with one running analysis takes 40 minutes using gradient elution. In this study, the relative $t_{R}$ of MA was 0.25 . The CP's theoretical plate was 1382 and the tailing factor was 2.76 . The standard CPM chromatogram detected four analytes besides MA and CP (Figure 1, Table 1). The four analytes were not confirmed their structure, whether they were identical with the $\mathrm{CP}$ related compounds. The system suitability (SST) requirements for CPM bulk material analysis were Rs between CP and CRCC NLT 1.5 and CP tailing factor NMT 2.0. The CP tailing factor in this study was not good but the shorter time analysis. The assay of CPM in CPM tablet in the reference (USP 39/NF 34, 2016) was UV spectrophotometry after long proses extraction, no SST requirement. As a note, the SST requirement of CPM in the CPM extended-release capsule was theoretical plate NLT 900 and tailing factor NMT 2.0.

The result of the accuracy and precision test fulfilled the AOAC requirement (AOAC International, 2013) and one running analysis takes 10 minutes. This selective and efficient method can be used as the method for determination CPM in the product development stage or in process control of CPM tablet production.

The stability of drug preparations showed the ability of a particular dosage form to maintain physical, chemical, therapeutic, and toxicity properties that had been determined in the monograph

Determination and stability ... (Damarwati et al.,) 
about identity, strength, quality, and purity (Kommana and Basappa, 2013). The result of the indication of stability was based on the impact of the degradation results of all compounds in CPM tablets. Forced degradation using heat, radiation, oxidation and acid hydrolysis did not influence the $\mathrm{CP}$ peak separation from tartrazine and the other degradants or impurities derived from matrix and CPM. However, degradation using $\mathrm{NaOH}$ shifted the $t_{R}$ of analytes and caused the CP peaks of artificial tablets and sample $\mathrm{Ze}{ }^{\circledR}$ split. Almost all degradation process using heat resulted in decreasing of CPM concentration. This result was identical to the results of previous research studies (Karikalan et al., 2016; Raghu et al., 2012).

\section{CONCLUSION}

The conclusion of this study is that the developed HPLC method suitable for the determination of CTM in tablets containing tartrazine. Nonetheless, a CPM stability indicating result after hydrolysis using $\mathrm{NaOH}$ was unsatisfactory and need to be study further

\section{ACKNOWLEDGEMENT}

Gratitude is due to the Directorate of Research and Community Services, Ministry of Research, Technology and Higher Education of Republic of Indonesia for funding, Faculty of Pharmacy of Universitas Airlangga for facilities and also thank you to Mr. M. Kusoiri for his helpfulness as an instrument operator.

\section{REFERENCES}

Alagić-Džambić, L., Vehabović, M., Čekić, E., \& Džambić, M. (2014). Development and Validation of a HPLC Method for Chlorphenamine Maleate Related Substances in Multicomponents Syrups and Tablets. International Journal of Pharmacy Teaching \& Practices, 5(3), 997-1001.

Ali, A., Ahmed, M., Mahmud, T., Qadir, M., Nadeem, K., \& Saleem, A. (2016). Stability-indicating High-performance liquid chromatography method for simultaneous determination of aminophylline and chlorpheniramine maleate in pharmaceutical formulations. Indian Journal of Pharmaceutical Sciences, 77(5), 515. https://doi.org/10.4103/0250-474x.169042

Ali, H., Shoaib, M. H., \& Bushra, R. (2011). Formulation development of chlorpheniramine maleate tablet by direct compression. Jordan Journal of Pharmaceutical Sciences, 4(1), 1-8.

AOAC International. (2013). AOAC Official Methods of Analysis - Appendix K: Guidelines for Dietary Supplements and Botanicals. 32.

Blessy, M., Patel, R. D., Prajapati, P. N., \& Agrawal, Y. K. (2014). Development of forced degradation and stability indicating studies of drugs - A review. Journal of Pharmaceutical Analysis, 4(3), 159-165. https://doi.org/10.1016/j.jpha.2013.09.003

Chlorpheniramine Maleate. (2016a). In The United States Pharmacopeia 39/The National Formulary 34,Vol 2 (pp. 3121-3125). The United states Pharmacopoeial Convention.

Chlorpheniramine Maleate. (2016b). In British Pharmacopoeia 2016 (pp. I-527-I-529). The Stationary office.

Darwish, H. W., Metwally, F. H., \& El Bayoumi, A. (2015a). Development of three methods for simultaneous quantitative determination of chlorpheniramine maleate and dexamethasone in the presence of parabens in oral liquids. Tropical Journal of Pharmaceutical Research, 14(1), 153161. https://doi.org/10.4314/tjpr.v14i1.22

Darwish, H. W., Metwally, F. H., \& El Bayoumi, A. (2015b). Discrete wavelet transform-partial least squares versus derivative ratio spectrophotometry for simultaneous determination of chlorpheniramine maleate and dexamethasone in the presence of parabens in pharmaceutical dosage form. Tropical Journal of Pharmaceutical Research, 14(5), 859-867. https://doi.org/10.4314/tjpr.v14i5.17

Karikalan, M., Priya, M. G. ., \& Shanmugapandiyan, P. (2016). Stabilitty indicating method 
development and validation for the quantification of chlorphenamine maleate related subtances using hplc technique. International Journal of Pharma and Bio Sciences, 7(4), 240-244. https://doi.org/10.22376/ijpbs.2016.7.4.p240-244

Klorfeniramin Maleat. (2014). In Farmakope Indonesia (5th ed., pp. 688-690). DepKes RI.

Kommana, R., \& Basappa, P. (2013). Validated Stability Indicating RP-HPLC Method for Simultaneous Estimation of Codeine Phosphate and Chlorpheniramine Maleate from Their Combined Liquid Dosage Form. Chromatography Research International, 2013, 1-7. https://doi.org/10.1155/2013/404727

Raghu, M. S., Basavaiah, K., Ramesh, P. J., Abdulrahman, S. A. M., \& Vinay, K. B. (2012). Development and validation of a UV-spectrophotometric method for the determination of pheniramine maleate and its stability studies. Journal of Applied Spectroscopy, 79(1), 131-138. https://doi.org/10.1007/s10812-012-9574-6

Saleh, T. A. (2011). Sensing of chlorpheniramine in pharmaceutical applications by sequential injector coupled with potentiometer. Journal of Pharmaceutical Analysis, 1(4), 246-250. https://doi.org/10.1016/j.jpha.2011.09.002

Srinivasan, J. R., Ph, D., Kawamura, Y., \& Ph, D. (2016). 82nd JECFA - Chemical and Technical Assessment ( CTA ), 2016 (C) FAO 2016 ROSEMARY EXTRACT Chemical and Technical Assessment ( CTA ). 5957, 1-7. 
